\title{
Fuzzy-Variable Gain PI Mode Control Applied to a Brushless AC Motor Drive
}

\author{
Fanambinantsoa Philibert Andriniriniaimalaza ${ }^{1,}$, , Nirinarison Jean Razafinjaka ${ }^{1}$, \\ Charles Bernard Andrianirina ${ }^{2}$ \\ ${ }^{1}$ Higher Polytechnic School, University of Antsiranana, Antsiranana, Madagascar \\ ${ }^{2}$ Science and Technology's Higher Institute, University of Mahajanga, Mahajanga, Madagascar
}

Email address:

philibert.andriniriniaimalaza@gmail.com (F. P. Andriniriniaimalaza), razafinjaka@yahoo.fr (N. J. Razafinjaka), nirina.cha.ca@gmail.com (C. B. Andrianirina)

*Corresponding author

\section{To cite this article:}

Fanambinantsoa Philibert Andriniriniaimalaza, Nirinarison Jean Razafinjaka, Charles Bernard Andrianirina. Fuzzy-Variable Gain PI Mode Control Applied to a Brushless AC Motor Drive. Engineering and Applied Sciences. Vol. 4, No. 1, 2019, pp. 1-10. doi: $10.11648 /$ j.eas.20190401.11

Received: December 10, 2018; Accepted: January 11, 2019; Published: February 27, 2019

\begin{abstract}
More strategies were developed to control a Brushless Motor's Speed. Among them, vector control is one of widely used. Variable Gain PI controller is developed and gives a performed control result. Fuzzy logic control is proposed to optimize the control system. In this paper, the system combines the performance of the Variable Gain PI and fuzzy logic controllers. All these strategies were simulated with Matlab and Simulink for comparison. Behind this, the main objective is to improve the best performance of the Fuzzy-Variable Gain PI mode control applied to a Brushless AC Motor drive where implementations, to an MSK23335 Board with a PM50 module and a 90W BLAC Motor, are shown to improve the result.
\end{abstract}

Keywords: Brushless Motor, Variable Gain PI, Fuzzy Logic, Hybrid Controller

\section{Introduction}

Brushless motors were appeared when the power electronic evolution is combined with the use of microcomputer [1]. These motors are the family of the Permanent Magnet Synchronous Motor which could be used into a various applications, such as, in industries, in robotics, in hybrid electric vehicles [2].

Characteristics are obtained by mathematical modelling of the system which are the important stage before an application of a control strategy [3].

Vector control helps the system to have the same performance with a DC Motor. This strategy is more exploited in an industrial application [4].

In [5], Razafinjaka and al. develops and proposes a method using a Variable Gain PI control strategy to optimize the PI control techniques applied to Wind Energy Control System. This control strategy is proposed to improve his performance with the Brushless motor control scheme.

The fuzzy logic controller is an attractive choice when precise mathematical formulations are not possible [6] and [7].

This strategy was developed and allows to obtain control performance compared with the classical controller for the applied system [8].

The hybrid controller was developed to combine the performance of the Variable Gain PI and the Fuzzy Logic controllers [9].

The algorithm of these control strategies is implemented to an MSK board to validate and improve the performance and robustness of the proposed hybrid system [10].

Firstly, all the part of the motor were modeled. Then, Vector control is given. The method using a Variable Gain PI is presented. And the Fuzzy Logic Control strategy is shown.

The hybrid controller is briefly described before applying its strategy to the control system. Simulation and experimental results of all these methods and their comparison are discussed. Finally, the conclusion gives the main scope of the proposed study. 


\section{System's Presentation}

The system, showed by figure 1 , is composed of a DC Sources or an AC/DC converter, the three phase PWM
Inverter, the controller and the Brushless Motor.

Closed loop control of the brushless motor is used to minimize the presence of parameter variation and load disturbance [1].

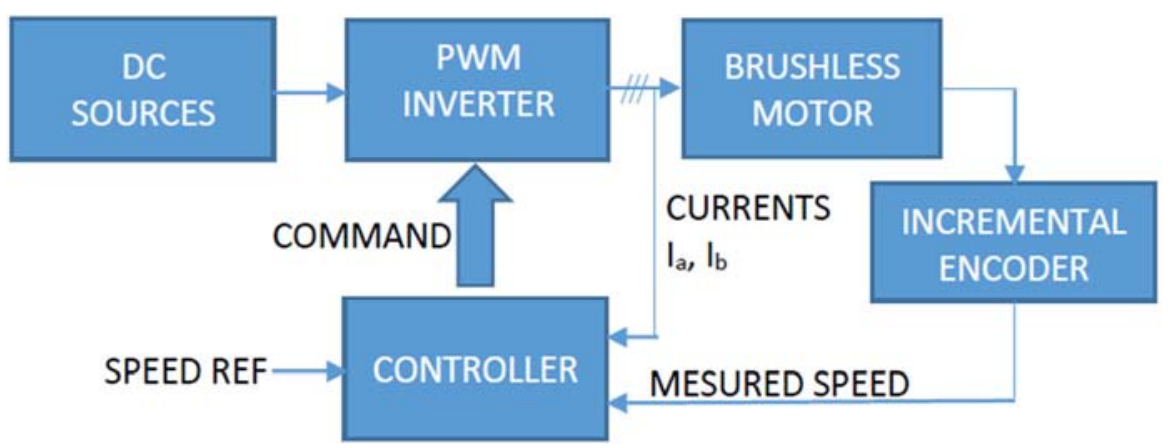

Figure 1. General scheme of the proposed system.

\section{Modelling Of the Brushless Motor}

\subsection{Electrical Model}

A brushless motor, [1] and [2], can be modeled as,

$$
\left\{\begin{array}{l}
V_{a}=R_{a} i_{a}+\left(L_{a}-M\right) \frac{d i_{a}}{d t}+e_{a} \\
V_{b}=R_{b} i_{b}+\left(L_{b}-M\right) \frac{d i_{b}}{d t}+e_{b} \\
V_{c}=R_{c} i_{c}+\left(L_{c}-M\right) \frac{d i_{c}}{d t}+e_{c}
\end{array}\right.
$$

\subsection{Torque Equation}

The electromagnetic torque is expressed as according to currents and flux by:

$$
\mathrm{T}_{\mathrm{em}}=\frac{3}{2} \mathrm{p}\left[\left(\mathrm{L}_{\mathrm{d}}-\mathrm{L}_{\mathrm{q}}\right) \mathrm{i}_{\mathrm{d}} \mathrm{i}_{\mathrm{q}}+\emptyset_{\mathrm{f}} \mathrm{i}_{\mathrm{q}}\right]
$$

\subsection{Motion Model}

The electromagnetic torque is expressed as according to currents and flux by:

$$
J_{m} \frac{d \Omega}{d t}+f \Omega=T_{e m}-T_{m}
$$

where, $\mathrm{J}_{\mathrm{m}}$ : the total inertia, $\mathrm{f}$ : the viscous friction coefficient.

\subsection{Park d-q Model for a BLAC Motor}

Then, in the static $\mathrm{d}-\mathrm{q}$ presentation, a brushless dc motor can be presented by:

$$
\left\{\begin{array}{c}
\mathrm{V}_{\mathrm{d}}=\mathrm{R}_{\mathrm{d}} \mathrm{i}_{\mathrm{d}}+\mathrm{L}_{\mathrm{d}} \frac{\mathrm{di}_{\mathrm{d}}}{\mathrm{dt}}-\omega \mathrm{L}_{\mathrm{q}} \mathrm{i}_{\mathrm{q}} \\
\mathrm{V}_{\mathrm{q}}=\mathrm{R}_{\mathrm{q}} \mathrm{i}_{q}+\mathrm{L}_{\mathrm{q}} \frac{\mathrm{di}_{\mathrm{q}}}{\mathrm{dt}}+\omega\left(\mathrm{L}_{\mathrm{d}} \mathrm{i}_{\mathrm{d}}+\phi_{\mathrm{f}}\right)
\end{array}\right.
$$

\section{The PWM Inverter}

The Figure 2 presents the principle of the PWM Sine Triangle on this study.

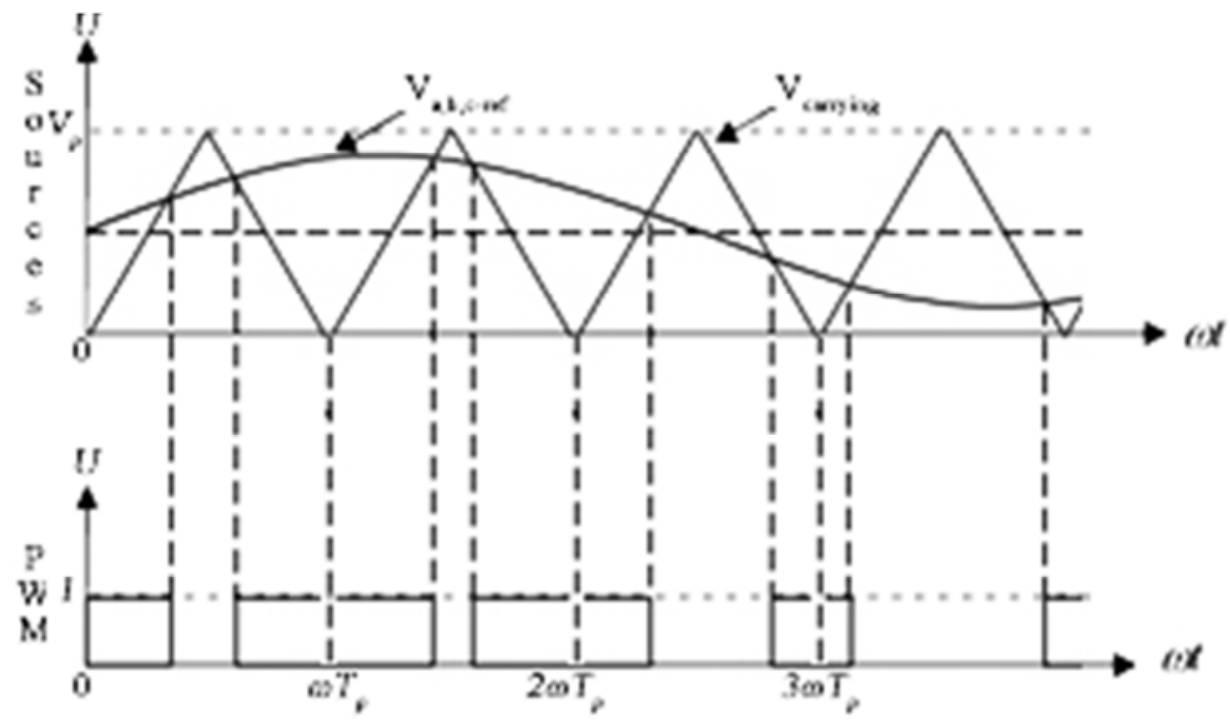

Figure 2. The used PWM Techniques. 
The inverter is modeled by:

$$
\left[\begin{array}{c}
\mathrm{V}_{\mathrm{an}} \\
\mathrm{V}_{\mathrm{bn}} \\
\mathrm{V}_{\mathrm{cn}}
\end{array}\right]=\frac{\mathrm{V}_{\mathrm{dc}}}{3}\left(\begin{array}{ccc}
2 & -1 & -1 \\
-1 & 2 & -1 \\
-1 & -1 & 2
\end{array}\right)\left[\begin{array}{l}
\mathrm{S}_{\mathrm{a}} \\
\mathrm{S}_{\mathrm{b}} \\
\mathrm{S}_{\mathrm{c}}
\end{array}\right]
$$

\section{Control Strategy}

In this part, vector control, Variable Gain PI mode control, fuzzy logic control and the hybrid controller are presented for more comprehension of control scheme.

\subsection{Vector Control}

This strategy [3] consists to replace the magnets by a spool crossed by a current constant $I_{f}$ which produces a flux equivalent to the one of the magnets.

$$
\left\{\begin{array}{c}
\mathrm{i}_{\mathrm{d}}=0 \\
\phi_{\mathrm{f}}=\mathrm{L}_{\mathrm{f}} \mathrm{I}_{\mathrm{f}}
\end{array}\right.
$$

Then, the electromechanical torque is defined by:

$$
\mathrm{T}_{\mathrm{em}}=\frac{3}{2} \mathrm{p} \phi_{\mathrm{f}} \mathrm{i}_{\mathrm{q}}
$$

The function transfer of a classical PI controller is given by,

$$
\mathrm{G}_{\mathrm{R}}(\mathrm{p})=\mathrm{K}_{\mathrm{p}}+\frac{\mathrm{K}_{\mathrm{i}}}{\mathrm{p}}
$$

\subsection{Variable Gain PI Controller Design}

A VGPI controller is a generalization of the classical PI controller where the proportional and integrator gains vary along a tuning curve.

Each gain of the proposed controller has four tuning parameters [4].

The VGPI controller in vector control of DFIG is used as presented in Figure 3.

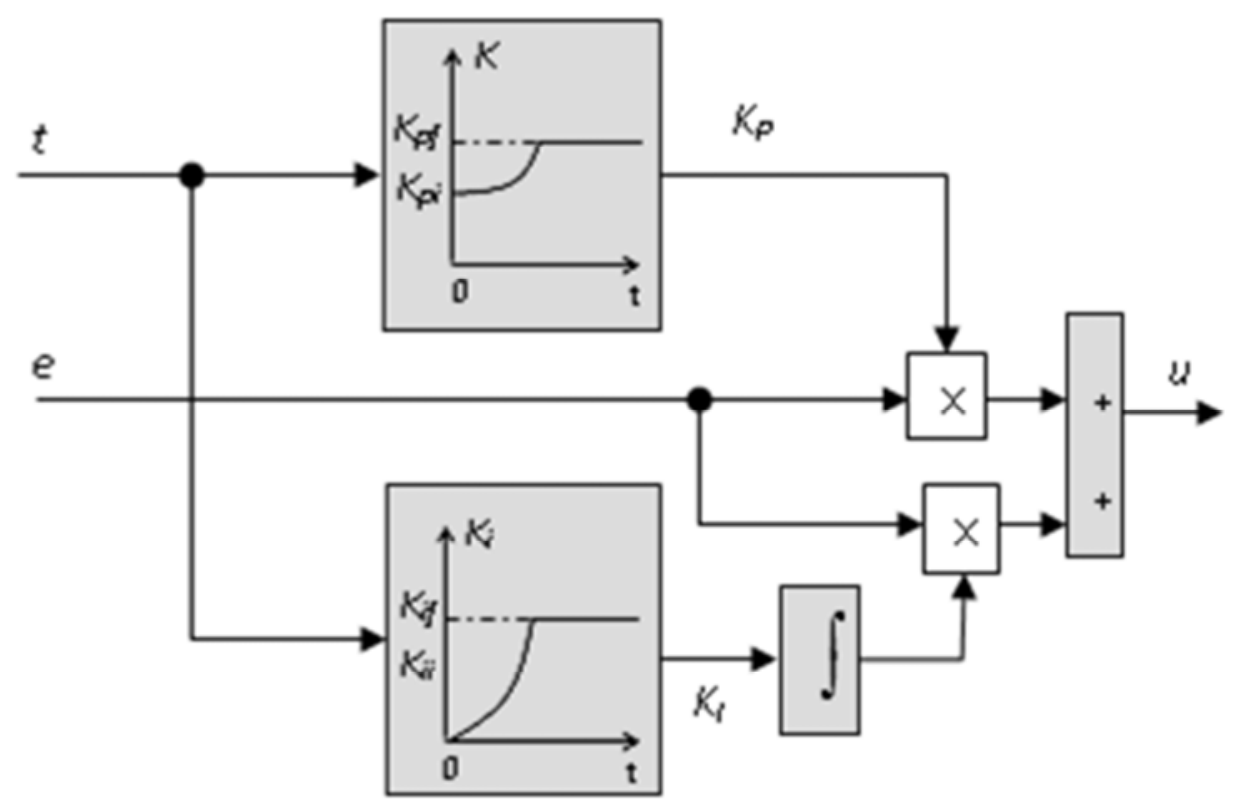

Figure 3. The VGPI Systems.

For the VGPI synthesis, the parameters of the PI classical controller and these classical PI controller gains are taken to be the terminal values of the VGPI controller.

These conditions are adopted:

$$
\mathrm{n}=1, \mathrm{Ts}=0,1[\mathrm{~s}]
$$

\subsection{The Fuzzy Logic Controller}

This method avoids modelling the process but having knowledge of its behavior is required. The reasoning is close to human perception.

Nowadays, the fuzzy controller begins to take an important place in electrical applications. It can be used for optimization and command, [5], [6] and [7]. The common scheme for a Fuzzy controller is given in Figure 4.

Fuzzification: in this state, physical variable are distributed on the domains variable which characterize this variable. It gave linguistic variable. 


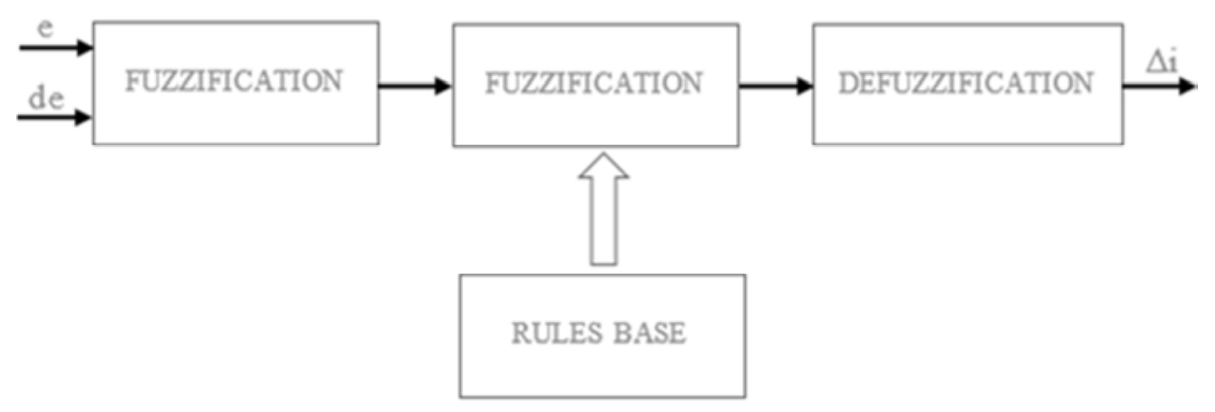

Figure 4. Structure of a fuzzy controller.

With, e: error, de: error variation, di: controller output

A precise measurement of the membership degree of the real variable to each fuzzy subset is possible.

Here, the inference method is adopted. It contains logical operation by which one admits a proposal under the terms of its relation with other proposals held for true.

And rules are established by the knowledge of the desired behavior of the system. An example is: (If $x_{1}$ is A) AND ( $x_{2}$ is B) THEN $s_{k}=C$, with: $x_{1} / x_{2}$ are the inputs, $s_{k}$ is the output representing the linguistic variable.

On this paper, the inputs are e (error) and de (variation of error). For the two inputs, the triangular and trapezoidal forms are used. The number of the membership functions of membership $\mathrm{N}=5$ is presented and adopted.

For the output, the function of membership of the output is as singleton referred with the Sugeno system. Table 1 gives the inference matrix.

Table 1. Rules base for $N=5$.

\begin{tabular}{lllllll}
\hline & & e & & & & \\
\hline & & NB & NS & Z & PS & PB \\
\hline & NB & NB & NB & NB & NS & Z \\
& NS & NB & NB & NS & Z & PS \\
de & Z & NB & NS & Z & PS & PB \\
& PS & NS & Z & PS & PB & PB \\
& PB & Z & PS & PB & PB & PB \\
\hline
\end{tabular}

The table gives nine rules. For example:

$\mathrm{R} 1: \operatorname{IF}(\mathrm{e}=\mathrm{NB}$ AND dE $=\mathrm{NB}) \operatorname{THEN}(\Delta \mathrm{i}=\mathrm{NB})$

Membership function may be also defined for the output variable. There are several inference methods, which may be applied.

Fuzzy variables is given by the results of the aggregation of the inference rules. On a real control system, all fuzzy variables must be translated into real or numerical variables: it is called defuzzification of variable.

Here, there are also some methods for the defuzzification. In this paper, the Sugeno's methods are chosen: for the fuzzy inference, a singleton is used as the membership function of the rule consequent combined by the (max-min) method for the rule evaluation.

The Sugeno defuzzification is then a weighted average method.

$$
S=\sum \frac{\mu\left(s_{k}\right) \cdot s_{k}}{\mu\left(s_{k}\right)}
$$

\subsection{Fuzzy VPGI mode Control}

The hybrid controller [8] is built on combination of this two topologies.

Figure 5 shows the block diagram of the fuzzy-VGPI controller system.

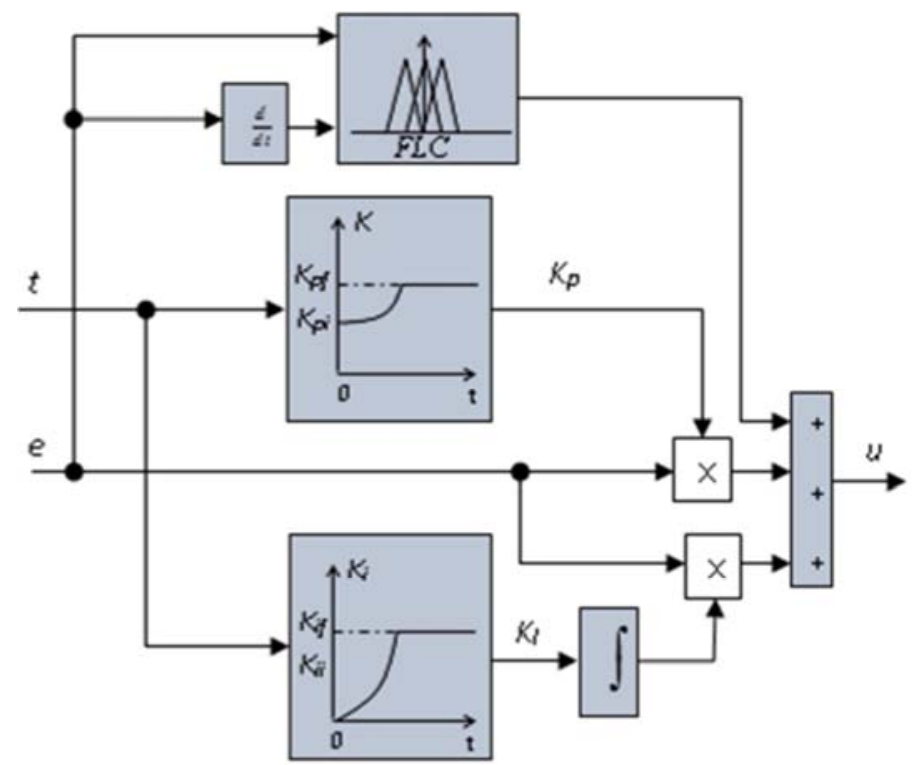

Figure 5. Basic scheme of proposed hybrid FUZZY-VGPI controller. 


\section{Results}

\subsection{Simulations}

Matlab Environment is used for the implementation of the brushless de motor modelling and control. And the model is presented by figure 6 below.

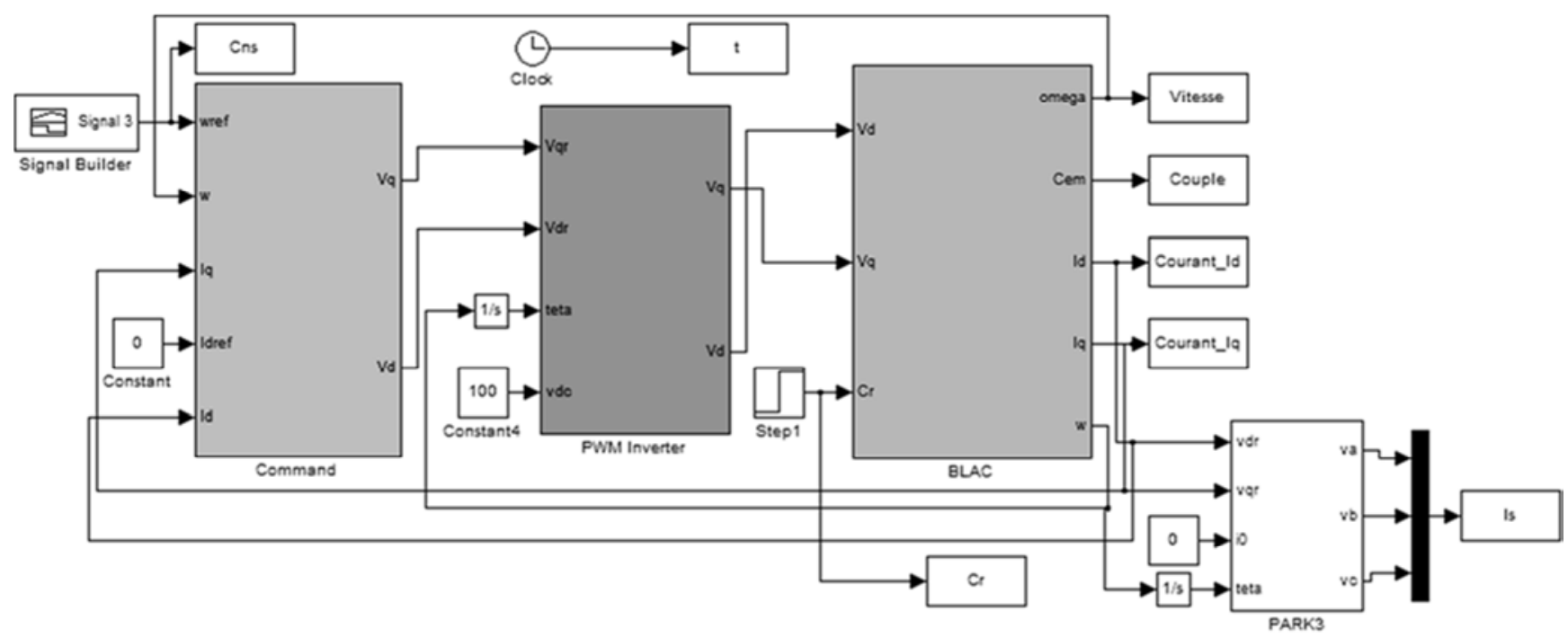

Figure 6. Model used for simulation in Matlab and Simulink.

Vector control, Variable Gain PI Mode Control, fuzzy logic control and the hybrid controller are used for evaluating the performance of each control strategy.

Table 2. Parameter of the Brushless AC Motor.

\begin{tabular}{lll}
\hline Nominations & Symbols & Values \\
\hline Resistance & $\mathrm{R}$ & $4.3[\mathrm{Ohms}]$ \\
Electrical Constant & TAU_EL & $82.8 \mathrm{e}^{-6}[\mathrm{~s}]$ \\
Torque Constant & $\mathrm{K}$ & $36.8 \mathrm{e}-3[\mathrm{Nm} / \mathrm{A}]$ \\
Inertia & $\mathrm{J}$ & $11.0 \mathrm{e}-7\left[\mathrm{Kgm}^{2}\right]$ \\
Friction Constant & $\mathrm{F}$ & $0.0[\mathrm{Nms} / \mathrm{rad}]$ \\
Number of lines & $\mathrm{NLines}$ & $500[$ lines/rot $]$ \\
Pair of pole & $\mathrm{p}$ & 1 \\
Power & $\mathrm{P}_{\mathrm{n}}$ & $90[\mathrm{~W}]$ \\
\hline
\end{tabular}

SPEED RESPONSE

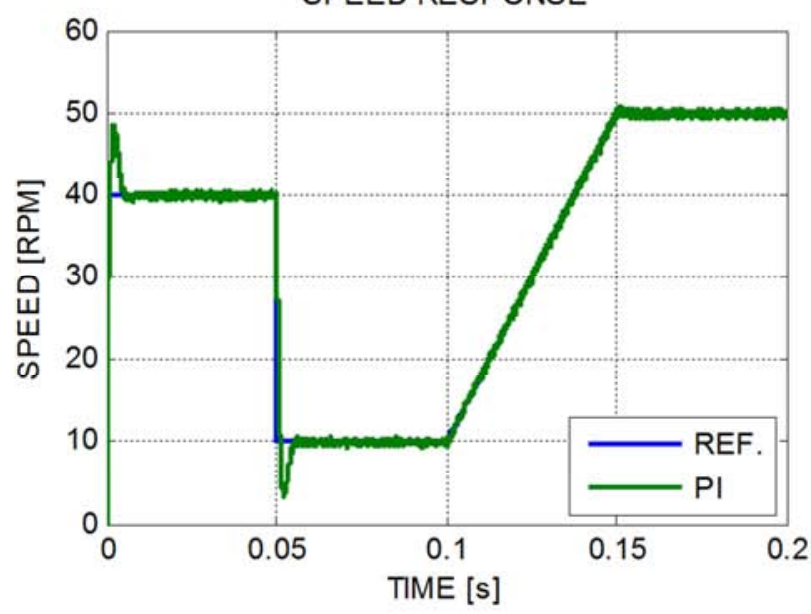

(a)
Table 3. Fuzzy logic parameters.

\begin{tabular}{ll}
\hline Constant & Value \\
\hline $\mathrm{ke}$ & $4.2 \mathrm{e}^{-4}$ \\
$\mathrm{kde}$ & 0.08 \\
$\mathrm{kdi}$ & 1000 \\
\hline & Table 4. VGPI control parameters. \\
& Value \\
\hline Constant & 2.5 \\
Degree of the regulator $(\mathrm{n})$ & $0.1[\mathrm{~s}]$ \\
\hline
\end{tabular}

Table 2, 3 and 4 give more information for all parameters used for simulation and experimentation.

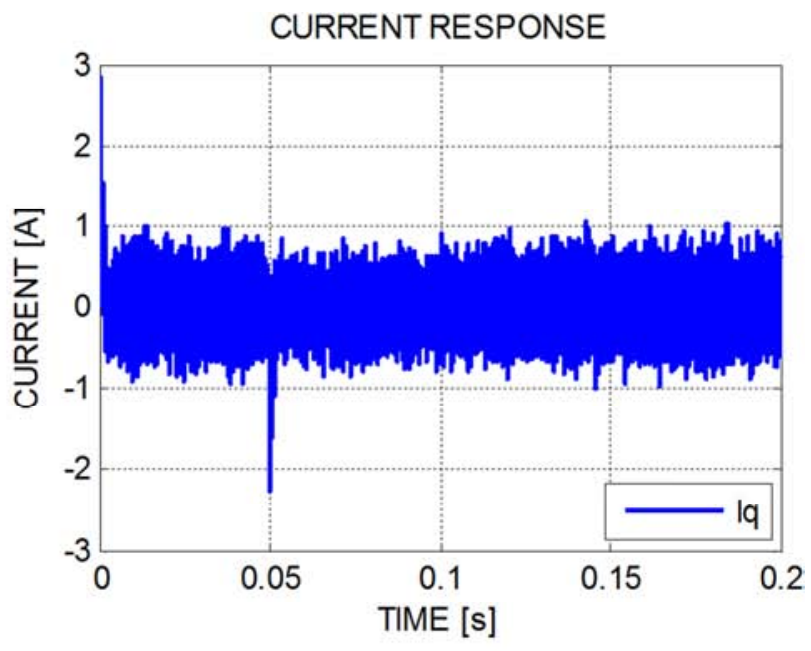

(b)

Figure 7. Simulation with a PI controller, (a): Speed, (b): Current. 


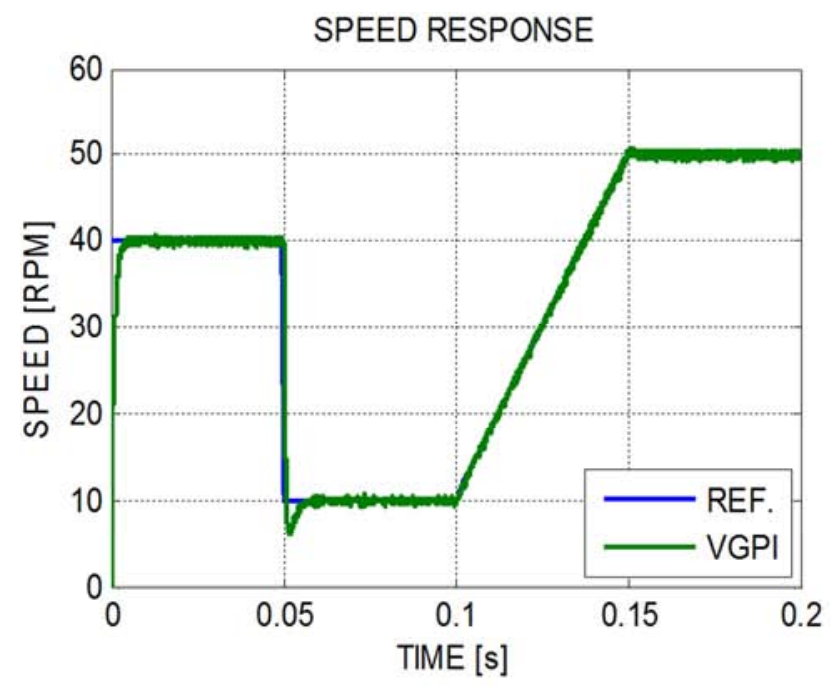

(a)

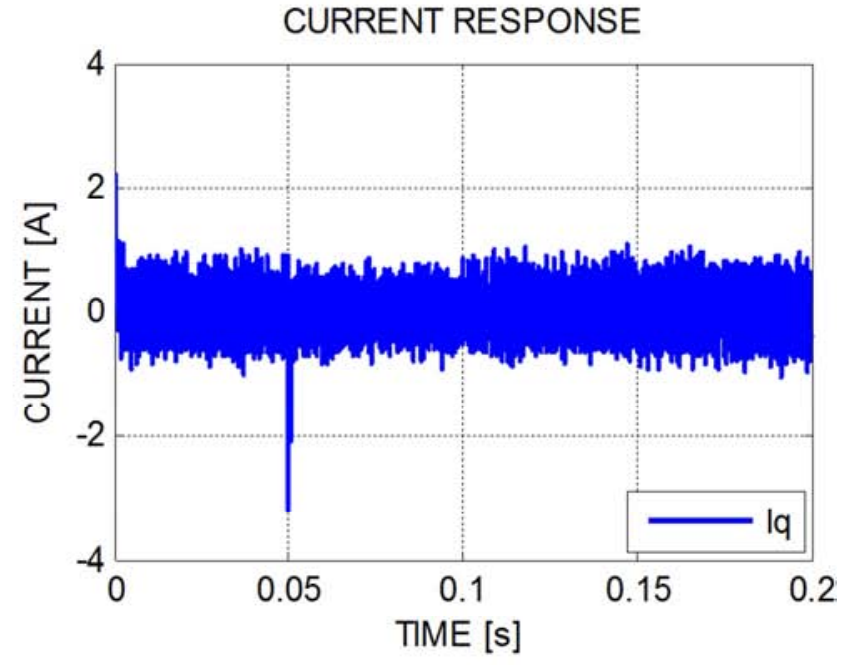

(b)

Figure 8. Simulation with a VGPI controller, (a): Speed, (b): Current.

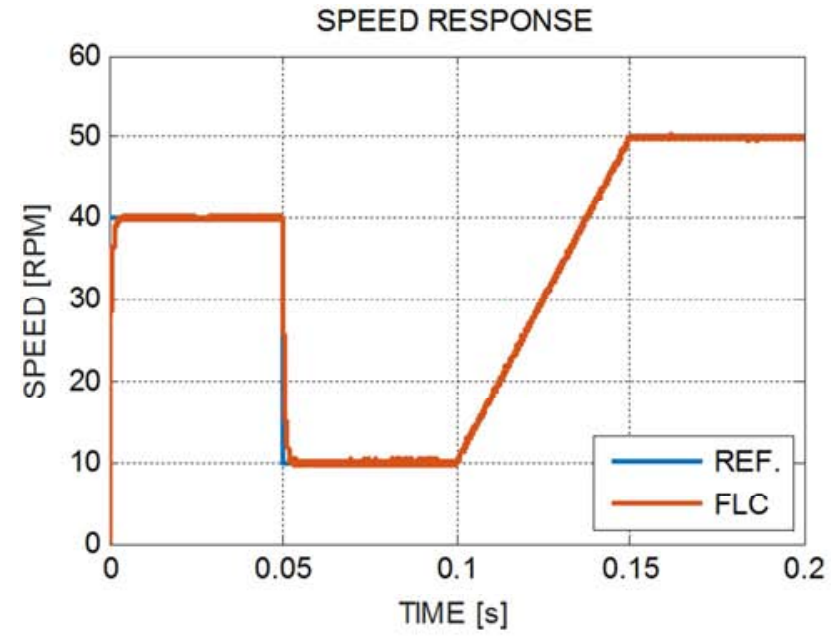

(a)

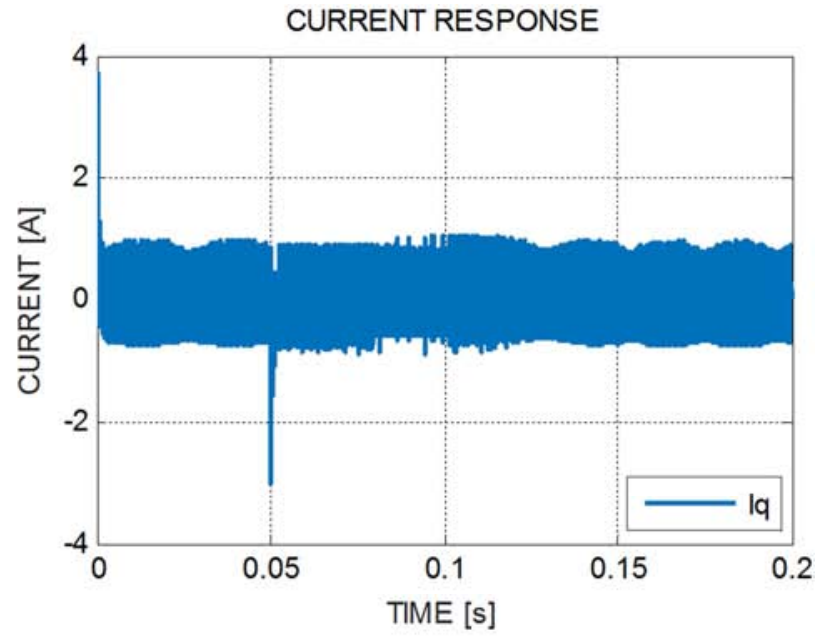

(b)

Figure 9. Simulation with a FLC controller, (a): Speed, (b): Current.

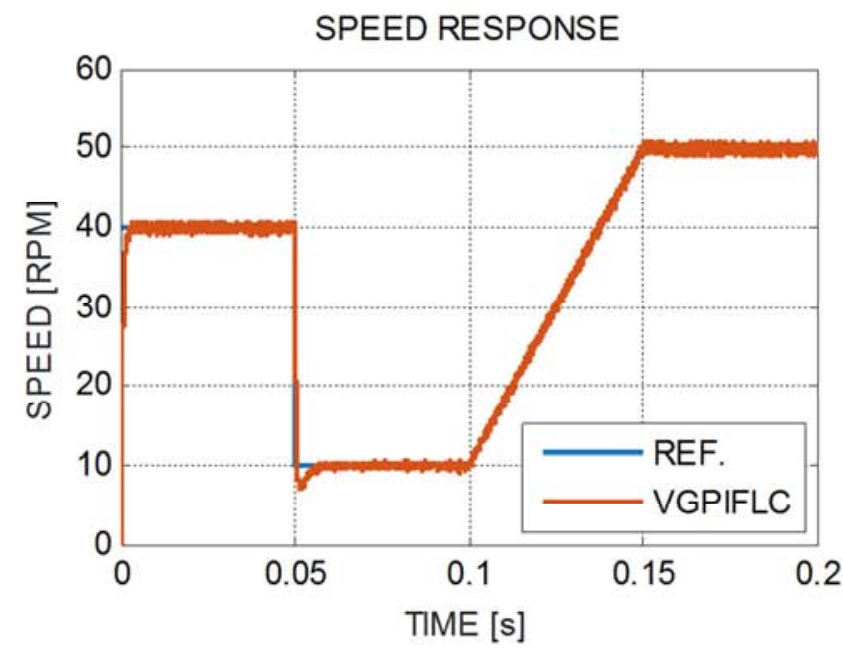

(a)

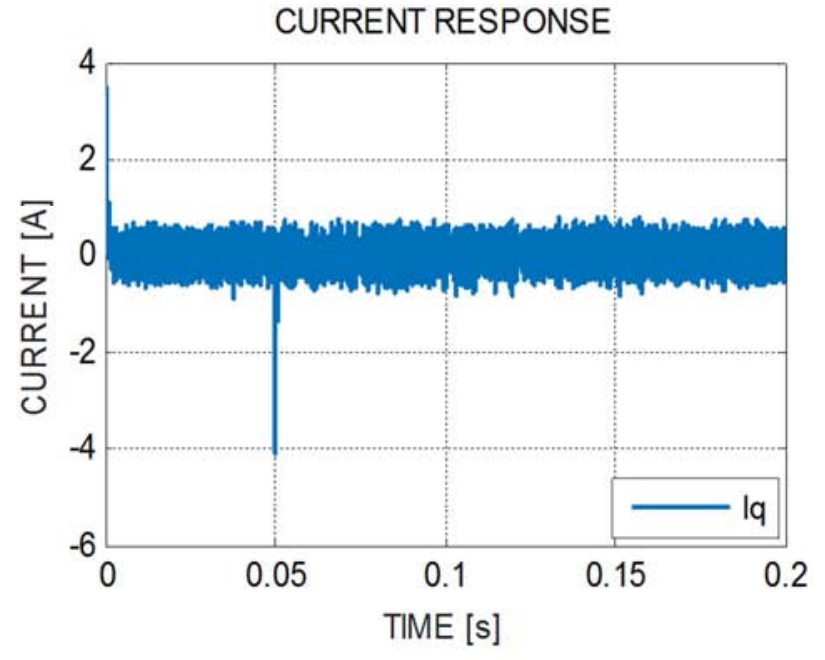

(b)

Figure 10. Simulation with a VGPI-FLC controller, (a): Speed, (b): Current. 
Figures 7, 8, 9 and 10 report the simulation results of all the controllers in Matlab environment applied of its motor. Robustness and performance of the hybrid Fuzzy-Variable Gain PI Controller are observed.

\subsection{Experimentations}

MSK23335 board is used for the implementation, [9] and [10], which all the parts are.

It is composed by:

- 1 , is the DSP controller and the power supply,

-2 , is the BLAC motor,

- 3 , is an intelligent controller for commanding the load effect in a specified time,

-4 , is the load (another BLAC motor).

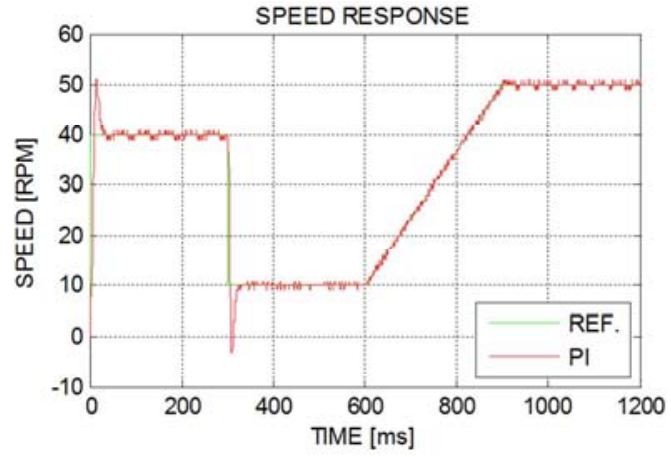

(a)

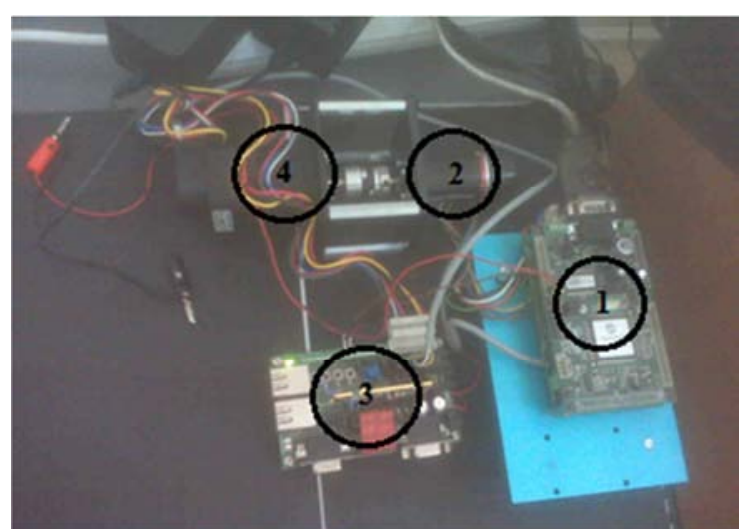

Figure 11. The development Kit.

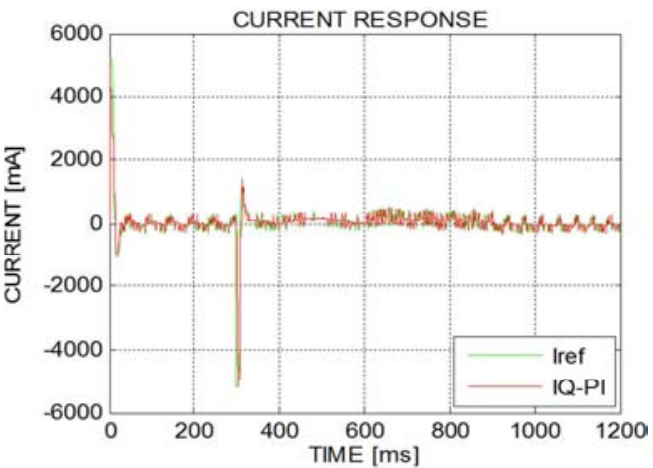

(b)

Figure 1. Results with a PI controller, (a): Speed, (b): Current.

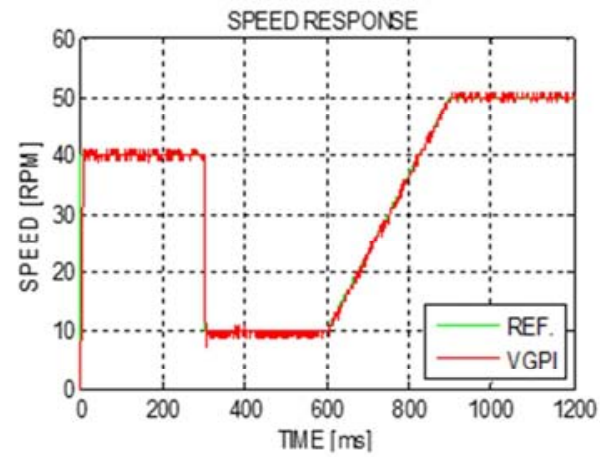

(a)

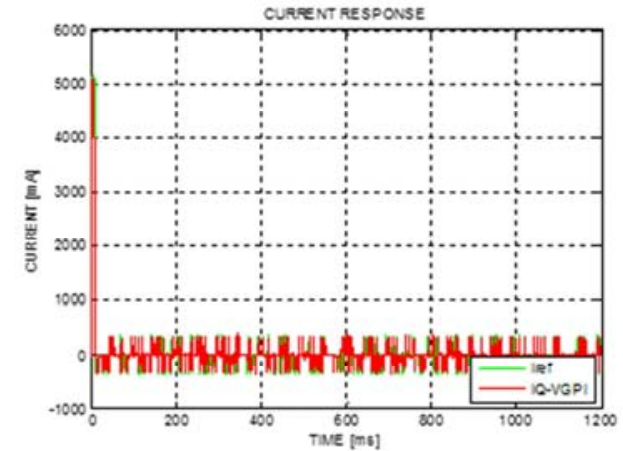

(b)

Figure 13. Results with a VGPI controller, (a): Speed, (b): Current.

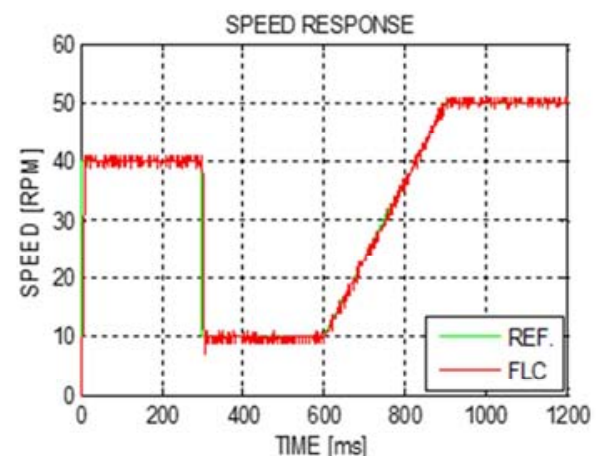

(a)

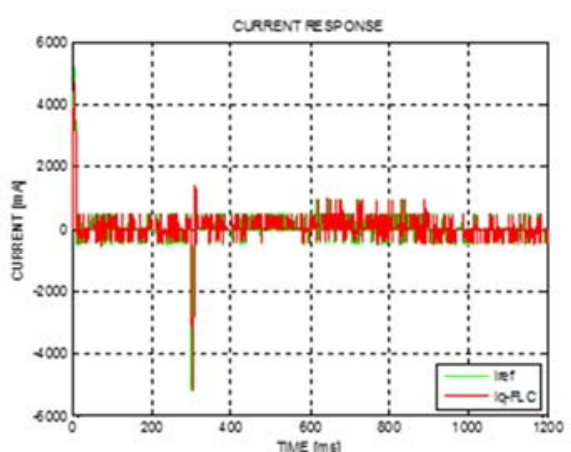

(b)

Figure 14. Results with a FLC controller, (a): Speed, (b): Current. 


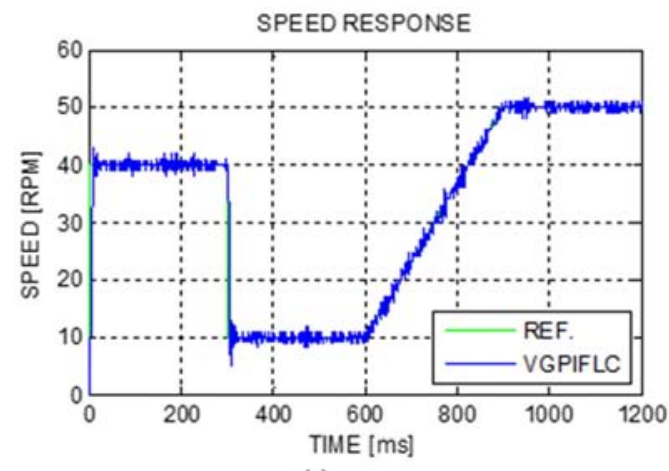

(a)

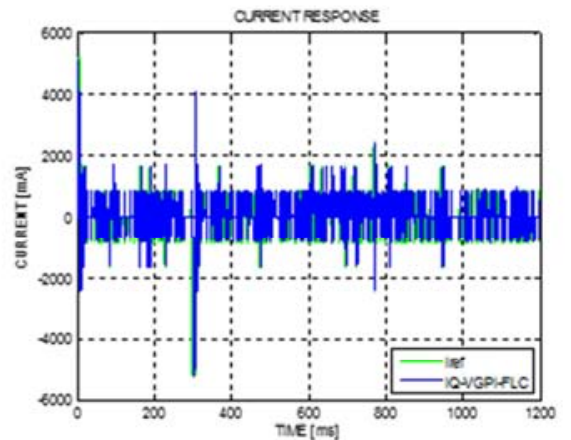

(b)

Figure 15. Results with a VGPI-FLC controller, (a): Speed, (b): Current.

Figures 12, 13, 14 and 15 show the results of the implementation into the development kit. (a) is concerning the speed response for a 40 [RPM] between 0 to 0.05 [s], a 10 [RPM] between 0.05 to 0.1 [s], a 10 to 50 [RPM] between 0.1 to 0.15 [s] and a $50[\mathrm{RPM}]$ after 0.15 [s], of reference and (b) is referring to the Iq response for both controller's configuration.

The fuzzy-variable gain PI mode control gives interesting performances in tracking and in disturbance rejection.

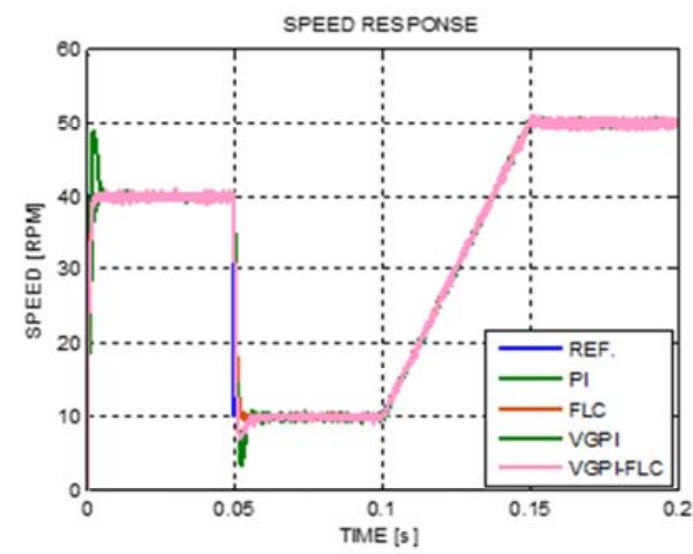

(a)

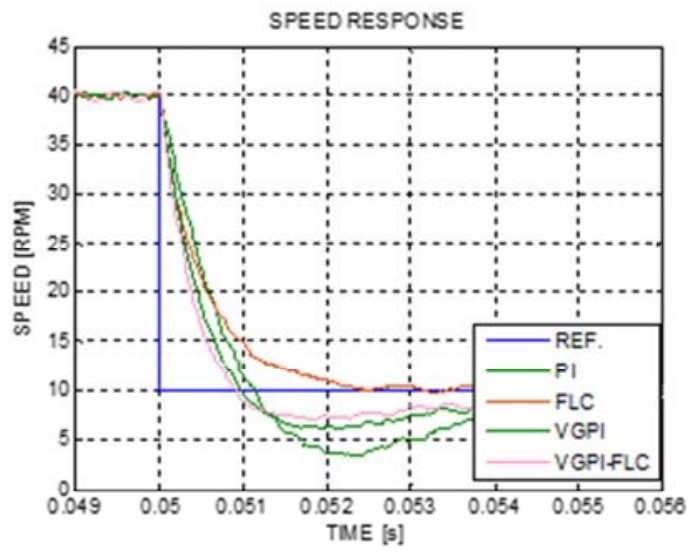

(c)

\section{Discussions}

\subsection{Simulation Results Comparison}

Figure 16 below is the details of the simulations results below. (a) shows all the results. (b) gives a zoom at the start time. In (c), at 0.05 [s], the fuzzy-variable gain mode control continues to stay away even if the consign is changed to 10 [RPM].

Then, the use of fuzzy-sliding mode control to the system rejects the perturbation and reduces the overshoot.

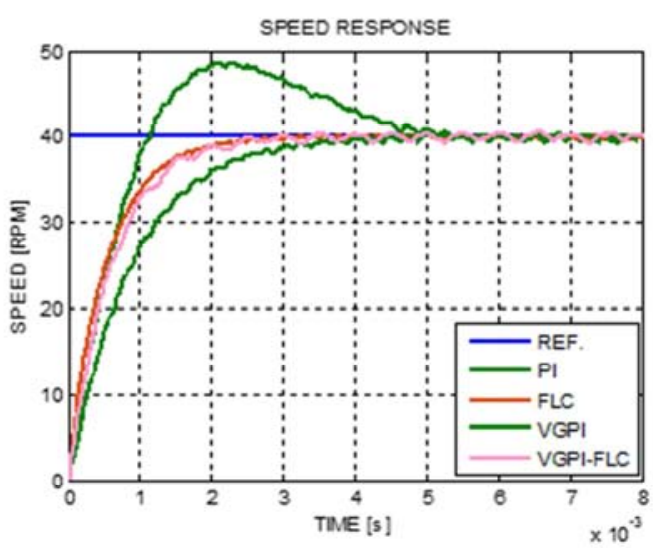

(b)

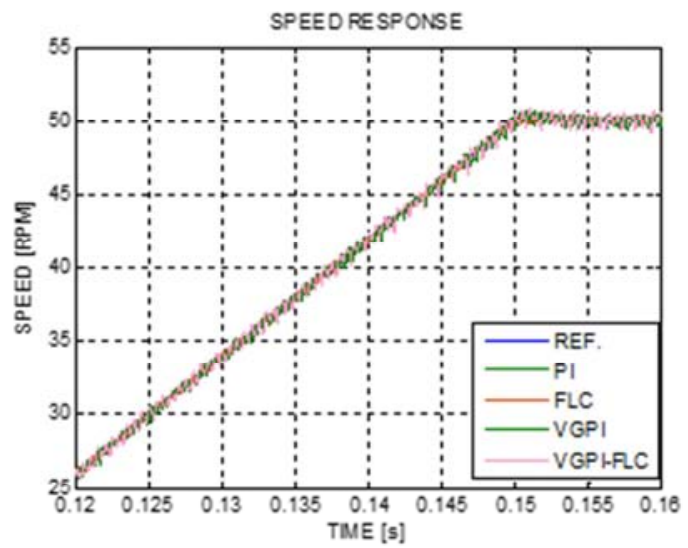

(d)

Figure 16. Simulations Speed Results, (a): Comparison, (b): Zoom 1, (c): Zoom 2, (d): Zoom 3. 


\subsection{Experimental Results Comparison}

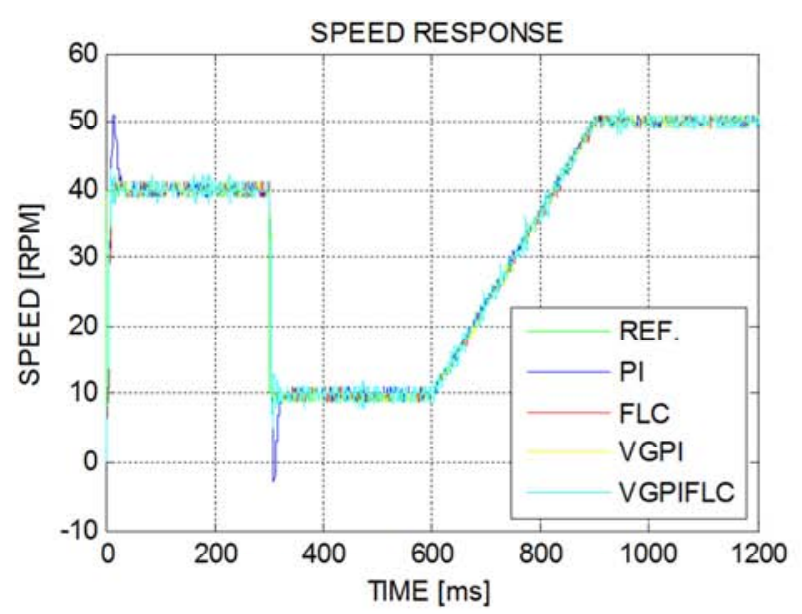

(a)

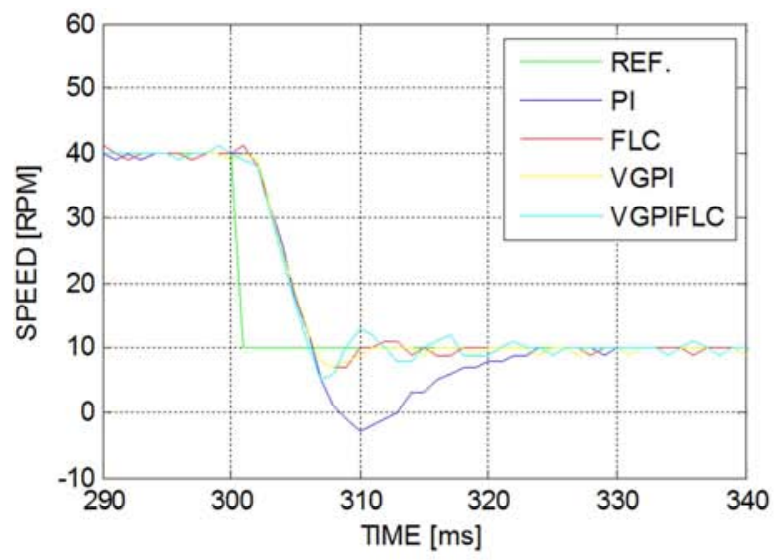

(c)

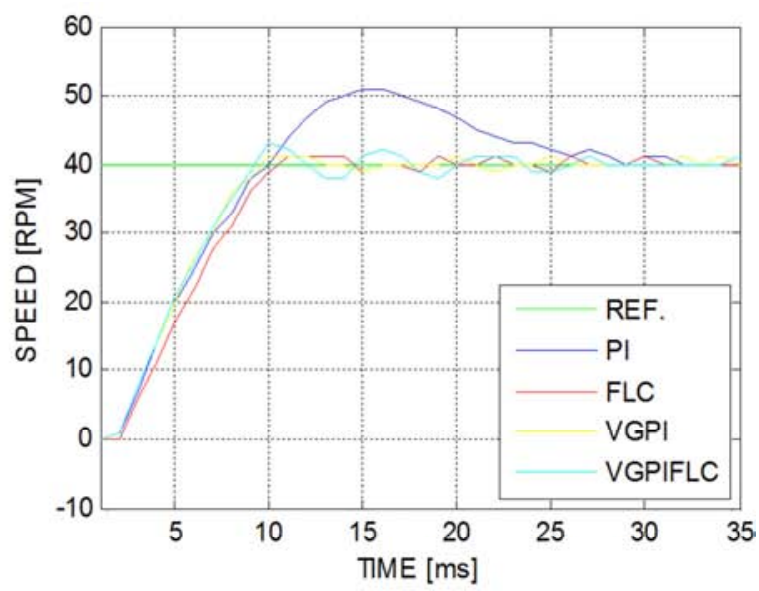

(b)

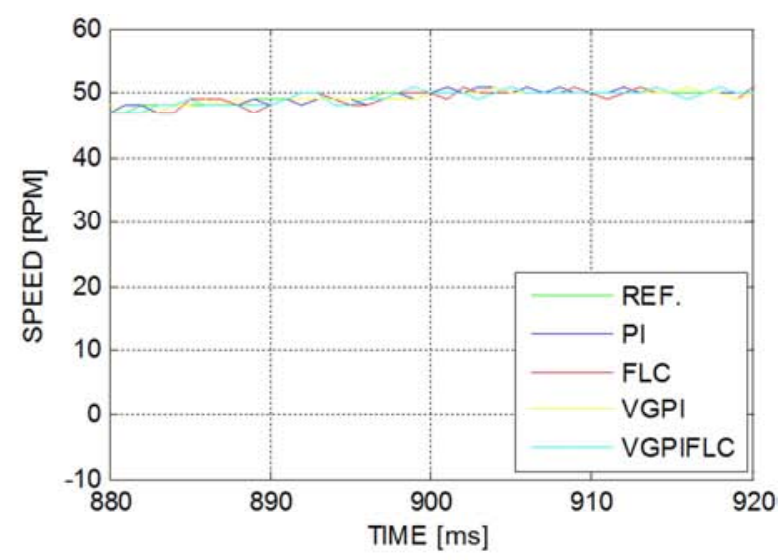

(d)

Figure 17. Experimental Results of the speed, (a): Comparison, (b): Zoom 1, (c): Zoom 2, (d): Zoom 3.

All the experimental results are resumed in Figure 16 (a). The configuration used here is look like the simulation consign. In (b), the use of a fuzzy-variable gain PI mode control (VGPI-FLC) gives more conclude result for controlling the system.

All the results of the simulation and the experiment show that the proposed hybrid controller based on VGPI-FLC gives more significant result in disturbance rejection, good behavior in respect of variation parameter.

\section{Conclusion}

Vector control, Variable gain PI Control, Fuzzy Logic Control and Fuzzy-Variable gain PI mode control are used to control a Brushless AC Motor. Referring to the obtained result, effectiveness and performance of this method is verified, in this paper, and VGPI-FLC is the best controller.

\section{Acknowledgements}

Thanks to Prof. Dr. Ing. Liviu KREINDLER from the
University Polithenica of Bucarest, Romania, for helping us to use the MSK controllers for the experimentation.

\section{References}

[1] Morlaye Sekou CAMARA and al., «Modélisation et commande d'une génératrice synchrone à aimant permanant pour la production et l'injection des énergies offshores dans un réseau», Symposium de génie électrique. 8-9 juillet 2014, Cachan.

[2] Gwo-Jen Chiou, Jeng-Yue Chen, Yao-Chun Tung, Fuh-Shyang Juang, "Implementation of a novel brushless DC motor controller", The 12th IEEE Conference on Industrial Electronics and Applications (ICIEA), Siem Reap, Cambodia, 2017.

[3] O. Sandre-Hernandez, J. J. Rangel-Magdaleno, R. MoralesCaporal, "Implementation of direct torque control for a PM synchronous machine based on FPGA", Power Electronics (CIEP) 2016 13th International Conference on, pp. 155-160, 2016.

[4] W. K. WIBOWO, S. JEONG, "Genetic algorithm tuned PI controller on PMSM simplified vector control", Berlin Heidelberg, 2013. 
[5] Razafinjaka and al., "Commande par PI à gain variable d'un système Eolien à base de génératrice Asynchrone à double alimentation", Conférence International Plasma et Energies, (CIPE) 2016. 37-39.

[6] Andriniriniaimalaza and al., Parameter Optimization for a fuzzy logic control of a Permanent Magnet Brushless Motor, the 10th International Symposium on Advanced Topics in Electrical Engineering, March 23-25, 2017, Bucharest, Romania. Availlable: https://ieeexplore.ieee.org/document/7905123M.

[7] Bapayya Naidu Kommula, Venkata Reddy Kota, Mathematical modeling and fuzzy logic control of a brushless DC motor employed in automobile and industrial applications, IEEE First International Conference on Control, Measurement and Instrumentation (CMI), Kolkata, India, 2016.
[8] Razafinjaka and al., Fuzzy-Variable Gain PI Control of WECS based on a Doubly Fed Induction Generator, The international Conference on Modelling and Applied Simulation, 2017. 51.

[9] Meixi Wu, Yuchi Lin, Control System of Two-phase Brushless DC Gyro Motor Based on DSP, The Second International Conference on Instrumentation, Measurement, Computer, Communication and Control, Harbin, China, 2012.

[10] Ali Mousmi, Ahmed Abbou, Yassine El Houm, Trapezoidal control of Brushless DC motor based on DSP F28335, International Conference on Wireless Technologies, Embedded and Intelligent Systems (WITS), Fez, Morocco, 2017. 